\title{
A STUDY ON CLASSIFICATION OF ACUTE LEUKAEMIAS ON THE BASIS OF CHROMOSOMAL ABNORMALITIES AND MOLECULAR GENETICS
}

\section{S. Praveena $* 1$, B Indusree ${ }^{2}$.}

${ }^{* 1}$ Assistant professor, Pathology Department, Dr. Patnam Mahender reddy institute of medical sciences and Hospital, Chevella, Rangareddy, Telangana, India.

${ }^{2}$ Consultant Pathologist, Director, Shree Krishna Diagnostics, Hyderabad, Telangana, India.

\section{ABSTRACT}

During the 25 months of study from August 2010 to September 2012 a total of 36 cases of leukaemias were studied in the Department of pathology, Kakatiya Medical College, Warangal in collaboration with Lifeline Diagnostics, Hyderabad. Out of 36 cases, 20 cases were AML, 15 cases were ALL and 1 case was mixed phenotypic acute leukaemia. The highest number of cases in the adults belonged to AML (16 cases). In children ALL (13cases) formed the majority of cases followed by AML (4 cases). Male: female ratio was 1.76:1. Fever (61.1\%) was the most common presentation in the study population followed by splenomegaly (38.8\%). Out of the AML cases studied, 13 cases were diagnosed by morphology alone and in 5 cases, cytogenetic study helped in sub typing the cases. Out of the ALL cases studied 5 cases were diagnosed by morphology alone and in 3 Cases, cytogenetic studies confirmed the diagnosis. MPO stain was done on all cases of acute leukaemias and (20 cases) out of these showed positivity favoring a diagnosis of AML. PAS stain was done on all cases ( 7 cases) of which showed block positivity favoring a diagnosis of ALL. Immunophenotyping alone gave a definitive diagnosis in cases (25 cases). 1 case was diagnosed as mixed lineage acute leukaemia on Immunophenotyping which showed positivity for CD117, CD13, CD33, CD3, CD5. Only a total of 1 case failed on culture. Normal karyotying was seen in 26 cases. Cytogenetic studies helped in detecting other uncommon chromosomal abnormalities like hyper/ hyperploids states which paved way for prognostication of the study population. FISH was done only in 3 cases.

KEY WORDS: Acute Lymphoblastic Leukaemia, Acute Myeloid Leukaemia, Acute Myeloid Leukaemia-M4 Eosinophilic Variant, Acute Promyelocytic Leukaemia.

Address for correspondence: S. Praveena, Assistant professor, Pathology Department, Dr. Patnam Mahender reddy institute of medical sciences and Hospital, Chevella, Rangareddy, Telangana, India. E-Mail: praveena.bhushan@gmail.com

\begin{tabular}{|c|c|c|}
\hline \multicolumn{3}{|c|}{ Online Access and Article Informtaion } \\
\hline \multirow{2}{*}{ Quick Response code } & \multicolumn{2}{|c|}{$\begin{array}{l}\text { International Journal of Integrative Medical Sciences } \\
\qquad \text { www.imedsciences.com }\end{array}$} \\
\hline & $\begin{array}{l}\text { Received: 11-04-2018 } \\
\text { Reviewed: 11-04-2018 }\end{array}$ & $\begin{array}{l}\text { Accepted: } 22-04-2018 \\
\text { Published: } 30-04-2018\end{array}$ \\
\hline Source of Funding: Self & \multicolumn{2}{|c|}{ Conflicts of interest: None } \\
\hline
\end{tabular}

\section{BACKGROUND}

Leukemia is a type of cancer of the blood or bone marrow characterized by an abnormal increase of immature white blood cells or blasts. Leukemias are classified into two broad groups, if myelocytic cells or other cells derived from the CFU-GEMM (Colony forming unit-Granulocytic, Erythrocytic, Monocytic, Megakaryocytic) stem cell predominate, the disease is called myelogenous leukemia. If the lymphoid cells predominate, the disease is termed lymphocytic leukemia. These are associated with varied systemic involvement such as anemia, splenomegaly, generalised lymphadenopathy and petechial haemorrhagic spots. In 2010, globally, approximately 281,500 people died of leukemia [1]. In 2000, approximately 256,000 children and adults around the world developed a form of leukemia, and 209,000 died from it [2]. 
This represents about $3 \%$ of the almost seven million deaths due to cancer that year, and about $0.35 \%$ of all deaths from any cause [2]. For this reason, the clinician also requires the basic peripheral blood smear study as a preliminary examination to differentiate the various diseases that overlap the symptomatology of acute leukemia clinically. Diagnosing the type and sub-type of leukemia is very important as the therapy, prognosis and survival rate changes with each type and sub-type. Less than $15 \%$ of cases in children below 10years, $25-30 \%$ between $10-15$ years, and $80-90 \%$ of adults cases of acute myeloid leukaemia (AML) [3]. ALL constitutes over $80 \%$ of childhood cases and comprises of $12 \%$ of all leukemias [4].

The MIC (Morphology, Immunohistochemistry, and cytogenetics) classification incorporates leukemic cellular morphology, immunohistochemistry (IHC) and cytogenetics as three important criteria for the classification of leukemias [5]. Chromosomal abnormalities are important for the classification and diagnosis of the disorder. In acute leukemias, the karyotype may be an important and independent prognostic factor in predicting both remission achievement and the length of remission and in distinguishing potential long term survivors from those likely to fail on standard therapy [5].

Immunophenotyping by flow cytometry which detects the cell surface antigens is used to diagnose and classify acute leukemia as in some cases of AML lacking cytochemical staining(AML FAB MO) or identification of subtypes that have a different prognosis ( $B$ cell $A L L$ ) or require an alternate therapeutic regimen (AMLFAB M3) [6].

The combined evaluation of leukemias by morphology, cytogenetics and immunophenotyping is very important for an accurate diagnosis and for planning the treatment. Hence the present study is being conducted to diagnose and classify the type and subtype of leukemias by a combination of the above parameters.

\section{MATERIALS AND METHODS}

The study was done from August 2010 to September 2012.Peripheral blood and bone marrow aspirate samples received at the Department of Pathology, Kakatiya Medical College, and Warangal were studied in collabo- ration with Life Line Diagnostics, Hyderabad. Bone marrow aspirate and peripheral blood smear samples from patients of all age groups who present with abnormal haematological findings suggestive of leukaemia, presenting with hepatosplenomegaly \&lymphadenopathy, investigated for pyrexia of unknown origin, complaining of bone pain. Patients who drop out of the study before complete work-up, due to death or discharge against advice have been excluded from the study. The relevant clinical history was obtained in each case, routine blood counts performed and peripheral smears studied in detail. About $0.5-1 \mathrm{ml}$ of bone marrow sample was collected from each case in EDTA and heparinized tubes. Smears from EDTA samples were stained with standard Romanowsky stain (Leishman stain) and studied for morphology of cells. The Cytochemical stains with Myeloperoxidase Stain (MPO) and Periodic Acid Schiff Stain (PAS) was done in all cases for preliminary typing of leukaemia.

Bone marrow culture for cytogenetic analysis: About 2-4 drops of heparinised (sodium heparin) marrow was added to 2 culture tubes, each containing $8 \mathrm{ml}$ of RPMI-1640 medium supplemented with $20 \%$ fetal bovine serum. No mitotic stimulants were used. One culture was incubated at 37c for $24 \mathrm{hrs}$ and the other at $37 \mathrm{c}$ for $48 \mathrm{hrs}$. After 24 or $48 \mathrm{hrs}$ of incubation, $50 \mathrm{ml}$ of colcenoid $(10 \mu \mathrm{g} / \mathrm{ml})$ was added to the culture to arrest the cell division at metaphase stage, Culture was incubated for further 30 minutes, Except $0.5 \mathrm{ml}$, all supernatant was discarded, The cells were subjected to hypotonic treatment with $5 \mathrm{ml}$ of 0.075 Potassium chlorides with constant agitation, Cultures were incubated for $15 \mathrm{~min}$ at $37{ }^{\circ} \mathrm{C}$ and centrifuged at 1500 revolutions per minute for 3 minutes, The supernatant was discarded and freshly prepared fixative (Methanol: acetic acid in the ratio 3:1) was added drop by drop with constant agitation. This step was repeated thrice. The final concentration of cell suspension was adjusted visually after preparing and examining the test slide. Precleaned slide with ethyl alcohol was taken and a layer of fixative was run over it. 1 drop of cell suspension was dropped on to the wet slide from a height of 4-6 inches and air dried. The slides were incubated at $65^{\circ}$ over night before 


\section{GTG-banding.}

GTG Banding (G-banding using Trypsin and Giemsa stain): Coplin jar 1: Trypsin working solution: $50 \mathrm{ml}$ of normal saline (NS) was added to $5 \mathrm{mg}$ of trypsin powder, mixed well and allowed to stand for 10 minutes at room temperature. Coplin jar 2:50 ml of NS. Coplin jar 3: To $42 \mathrm{ml}$ of distilled water, $2.5 \mathrm{ml}$ each of sodium dihydrogen phosphate and Disodium hypophosphate solutions were added and to this, $3 \mathrm{ml}$ of water soluble Giemsa stain solution added, mixed well and the top layer removed using a filter paper. Coplin jar 4: $50 \mathrm{ml}$ of distilled water. Slides incubated at 65 were dipped in trypsin working solution (coplin jar 1) for 20-35 seconds. Slides were briefly rinsed in coplin jar 2 (NS). Slides were stained with buffered Giemsa (Coplin jar 3) for $10 \mathrm{~min}$. Slides were rinsed in distilled water (coplin jar 4) briefly, air dried. Banded slides were mounted with cover slips using DPX mountant. Thus GTG banding was done on these slides, and chromosomes analyzed. At least 20 metaphases were screened for structural and numerical abnormalities, and atleast 5 metaphases were karyotyped. Karyotypes were described according to the International System for Chromosomal Nomenclature (ISCN).

Fig. 1: Karyotype showing 46 chromosomes (46xx) in a case of B-lymphoblastic leukaemia.

$$
\text { (1) }
$$

Fig. 2: Karyotype showing 46 chromosomes (46XY) in a case of AML with maturation.

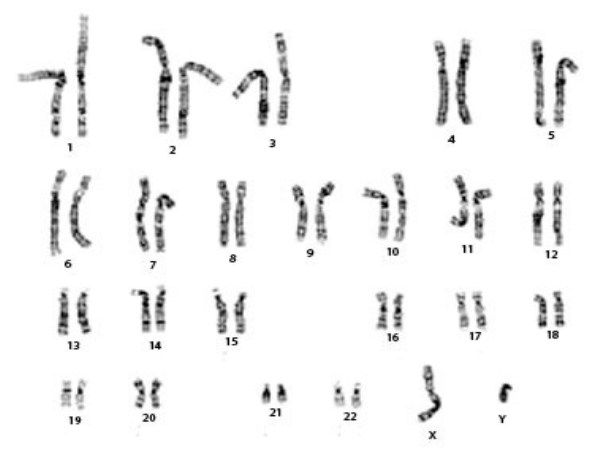

Fig. 3: Karyotype showing hyperploidy with 70 chromosomes in B-lymphoblastic leukaemia.

\section{Hir) Mir it ili}

\section{iii}

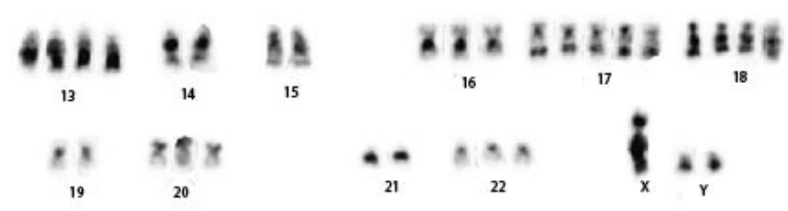

Fig. 4: Karyotype showing $46 \mathrm{XX}, \mathrm{t}(8 ; 21)$ in a case of Acute myeloid leukaemia.

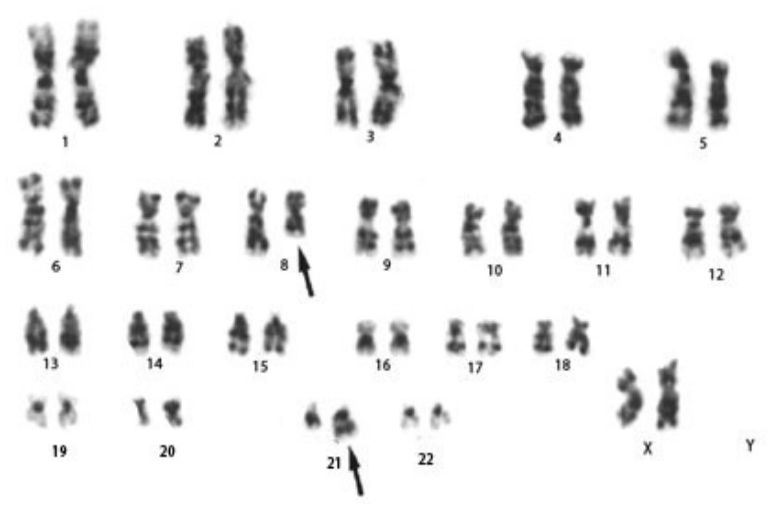

Fig. 5: Karyotype showing $46 \mathrm{XY}, \mathrm{t}(8 ; 21)$ in a case of Acute Myeloid Leukaemia.

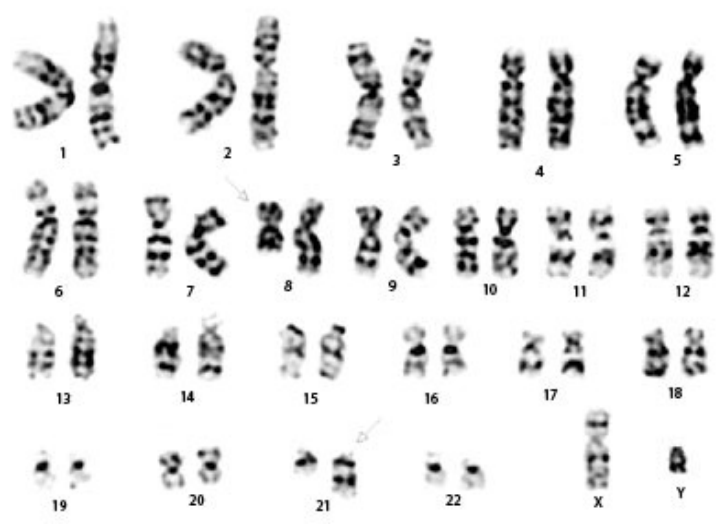

Fig. 6: Karyotype showing $46 \mathrm{XY} \mathrm{t}(15 ; 17)$ in case of Acute promyelocytic leukaemia.

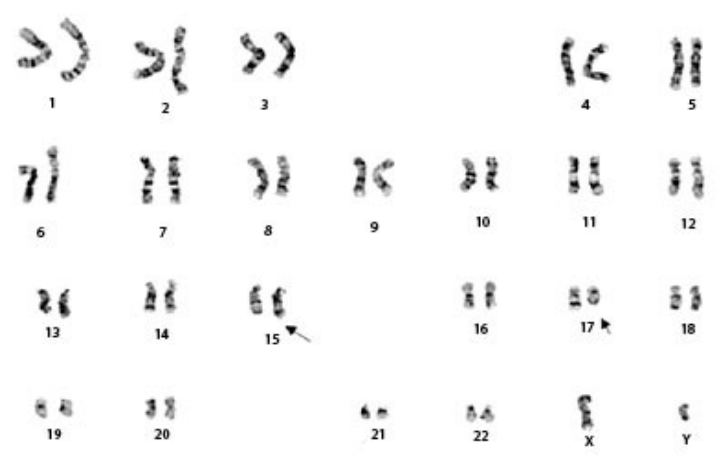


FISH: Fluorescence in situ hybridization (FISH) analyses were performed with commercially available probes according to the manufacturer's instructions. FISH was done on cultured unstimulated bone marrow cells/ blood smears using different probes to evaluate deletion/ translocation/break apart as requested as a part of the diagnostic evaluation required by the patient. Bone marrow (EDTA) samples were subjected to flow cytometry whenever necessary and affordable for the patient. The leukaemias were finally diagnosed and classified after correlating the clinical, haematalogical, and cytogenetic and immunophenotypic features.

\section{RESULTS}

Table 1: Showing the age distribution of acute leukaemias.

\begin{tabular}{|c|c|c|c|}
\hline Acute leukaemias & <18yrs & >18yrs & Total \\
\hline AML & 4 & 16 & 20 \\
\hline ALL & 13 & 2 & 15 \\
\hline $\begin{array}{c}\text { Mixed lineage Acute } \\
\text { leukaemia }\end{array}$ & 1 & 0 & 1 \\
\hline
\end{tabular}

Table 2: Showing the clinical manifestations of the study population.

\begin{tabular}{|c|c|c|}
\hline Clinical Manifestations & $\begin{array}{c}\text { Number of } \\
\text { cases }\end{array}$ & Percentage \\
\hline Easy fatigability & 3 & $16.70 \%$ \\
\hline Fever & 11 & $61.10 \%$ \\
\hline Hepatomegaly & 2 & $11.10 \%$ \\
\hline Splenomegaly & 7 & $38.80 \%$ \\
\hline Weakness & 2 & $11.10 \%$ \\
\hline Pallor & 1 & $5.60 \%$ \\
\hline Bleeding & 1 & $5.60 \%$ \\
\hline manifestations & 5 & $27.80 \%$ \\
\hline Lymphadenopathy & 1 & $5.50 \%$ \\
\hline Weight loss & 1 & $5.60 \%$ \\
\hline Cough & 2 & $11.10 \%$ \\
\hline Loss of appetite & & \\
\hline
\end{tabular}

Table 3: Diagnosis on peripheral blood smear examination.

\begin{tabular}{|c|c|c|c|c|}
\hline \multirow{2}{*}{ Final Diagnosis } & \multicolumn{3}{|c|}{ Peripheral smear report } & \multirow[b]{2}{*}{ Total } \\
\hline & $\begin{array}{c}\text { Acute } \\
\text { leukaemia }\end{array}$ & ALL & AML & \\
\hline $\begin{array}{l}\text { Mixed lineage } \\
\text { Acute leukaemia }\end{array}$ & 1 & 0 & 0 & 1 \\
\hline$\overline{\mathrm{ALL}}$ & 10 & 5 & 0 & 15 \\
\hline AML & 7 & 0 & 13 & 20 \\
\hline Total & 18 & 5 & 13 & 36 \\
\hline
\end{tabular}

Int J Intg Med Sci 2018;5(4):613-18. ISSN 2394 - 4137
Table 4: Diagnosis on bone marrow examination.

\begin{tabular}{|c|c|c|c|c|}
\hline \multirow{2}{*}{ Final diagnosis } & \multicolumn{3}{|c|}{ Bone marrow examination } & \multirow{2}{*}{ Total } \\
\cline { 2 - 4 } & $\begin{array}{c}\text { Acute } \\
\text { leukaemias }\end{array}$ & ALL & AML & \\
\hline $\begin{array}{c}\text { Mixed lineage } \\
\text { acute leukaemia }\end{array}$ & 1 & 0 & 0 & $\mathbf{1}$ \\
\hline ALL & 4 & 11 & 0 & $\mathbf{1 5}$ \\
\hline AML & 1 & 0 & 19 & $\mathbf{2 0}$ \\
\hline Total & $\mathbf{6}$ & $\mathbf{1 1}$ & $\mathbf{1 9}$ & $\mathbf{3 6}$ \\
\hline
\end{tabular}

Table 5: Diagnosis on cytochemistry.

\begin{tabular}{|c|c|c|}
\hline & $\begin{array}{c}\text { MPO STAIN } \\
\text { No of cases }\end{array}$ & $\begin{array}{c}\text { PAS STAIN } \\
\text { No of cases }\end{array}$ \\
\hline+ ve & 20 & 7 \\
-ve & 16 & 29 \\
Done & 36 & 36 \\
Not done & 0 & 0 \\
\hline Total & $\mathbf{3 6}$ & $\mathbf{3 6}$ \\
\hline
\end{tabular}

Table 6: Immunophenotyping done by flow cytometry.

\begin{tabular}{|c|c|}
\hline Lineage & $\begin{array}{c}\text { Confirmed by } \\
\text { immunophenotyping }\end{array}$ \\
\hline Myeloid & 9 \\
\hline T-Cell & 3 \\
\hline B-Cell & 12 \\
\hline Mixed lineage & 1 \\
\hline No of cases done & 25 \\
\hline Total case & 36 \\
\hline
\end{tabular}

Table 7: Diagnosis and typing of leukaemias on cytogenetic study.

\begin{tabular}{|c|c|c|c|c|c|c|c|}
\hline \multirow{2}{*}{ Final Diagnosis } & \multicolumn{6}{|c|}{ Cytogenetics } & \multirow[b]{2}{*}{ Total } \\
\hline & $\begin{array}{c}\text { Acute } \\
\text { leukaemias }\end{array}$ & ALL & AML & ALL>AML & Normal & Failed & \\
\hline $\begin{array}{l}\text { Mixed lineage } \\
\text { acute leukaemias }\end{array}$ & 0 & 0 & 0 & 0 & 1 & 0 & 1 \\
\hline ALL & 0 & 3 & 0 & 0 & 11 & 1 & 15 \\
\hline AML & 0 & 0 & 6 & 0 & 14 & 0 & 20 \\
\hline Total & 0 & 3 & 6 & 0 & 26 & 1 & 36 \\
\hline
\end{tabular}

Table 8: Number of chromosomes detected on karyotyping.

\begin{tabular}{|c|c|c|}
\hline $\begin{array}{c}\text { No of } \\
\text { chromosomes }\end{array}$ & frequency & percentage \\
\hline$<\mathbf{4 6}$ & 1 & $2.77 \%$ \\
\hline $\mathbf{4 6}$ & 30 & $83.30 \%$ \\
\hline$>\mathbf{4 6}$ & 4 & $11.10 \%$ \\
\hline Failed & 1 & $2.77 \%$ \\
\hline Total & 36 & $100.00 \%$ \\
\hline
\end{tabular}

Table 9: Diagnosis by fluorescence insitu hybridization.

\begin{tabular}{|l|c|c|}
\hline \multicolumn{1}{|c|}{ Diagnosis by FISH } & Frequency & Percentage \\
\hline AML with t(8;21)(q22;q22);RUNX1-RUNX1T1 & 1 & $2.70 \%$ \\
\hline APML with t(15;17)(q22;q12); PML-RARA & 1 & $2.70 \%$ \\
\hline AML with inv(16) (p13.1;q22) & 1 & $2.70 \%$ \\
\hline Done & 3 & $8.30 \%$ \\
\hline Not done & 33 & $91.60 \%$ \\
\hline Total & $\mathbf{3 6}$ & $\mathbf{1 0 0} \%$ \\
\hline
\end{tabular}


Table 10: Accurate final typing of leukaemias.

\begin{tabular}{|l|c|c|}
\hline \multicolumn{1}{|c|}{ Final diagnosis } & Frequency & Percentage \\
\hline AML with minimal differentiation & 4 & $11.10 \%$ \\
\hline AML without maturation & 2 & $5.50 \%$ \\
\hline AML with maturation & 4 & $11.10 \%$ \\
\hline Acute myelomonoblastic leukaemia & 1 & $2.70 \%$ \\
\hline Acute monoblastic leukaemia & 3 & $8.30 \%$ \\
\hline AML with t(8;21)(q22;q22);RUNX1-RUNX1T1 & 2 & $5.50 \%$ \\
\hline $\begin{array}{l}\text { Acute promyelocytic leukaemia with } \\
\text { t(15;17)(q22;q12); PML-RARA }\end{array}$ & 3 & $8.30 \%$ \\
\hline AML with inv(16) (p13.1;q22) & 1 & $2.70 \%$ \\
\hline B-lymphoblastic leukaemia (NOS) & 9 & $24.90 \%$ \\
\hline $\begin{array}{l}\text { B-lymphoblastic leukaemia/lymphoma with } \\
\text { hyperdiploidy }\end{array}$ & 3 & $8.30 \%$ \\
\hline $\begin{array}{l}\text { B-lymphoblastic leukaemia/lymphoma with } \\
\text { hypodiploidy }\end{array}$ & 0 & $0 \%$ \\
\hline T-lymphoblastic leukaemia & 3 & $8.30 \%$ \\
\hline \begin{tabular}{l} 
Mixed phenotypic acute leukaemia,T/Myeloid NOS \\
\hline
\end{tabular} & 1 & $2.70 \%$ \\
\hline
\end{tabular}

\section{DISCUSSION}

In the present study 36 cases of leukaemia were evaluated by morphology, cytochemistry, Immunophenotyping, cytogenetics, FISH to arrive at a final diagnosis. The duration of study was from August 2010 to September 2012.63.8\% of cases were males and $36.2 \%$ were females, the male female ratio being1 76:1 were participated in this study. Different types of leukaemias have different clinical presentations. In this study the most common clinical presentation of patients was fever followed by splenomegaly. Lymphadenopathy was the clinical presentation in children with ALL. The study of Koushal et al [7] found splenomegaly as the commonest presentation (81\%) followed by hepatomegaly (69\%) and fever (61\%). In the study done by Ghosh et al [8] pallor and weakness were the commonest clinical findings (82\%) followed by lymphadenopathy (36.2\%).

In the present study the majority of cases were AML (20 cases) followed by ALL (15 cases) and 1 case of mixed lineage acute leukaemia. Vinsheeth et al (9) in their study found CML as the commonest leukaemia (110 cases) followed by AML (18) and ALL (10). Present study is almost in concordance with other studies except for higher no of AML cases which could be due to population bias. In this study out of 20 cases of AML, AML-M2 with 4 cases was the commonest followed by M3 with 3 cases. This is in league with the study done by Ghosh et al [8] with AML$\mathrm{M} 2$ being the commonest subtype in adults $(32 \%)$ and also in children (42\%). MPO and PAS stain was done on all 36 cases of acute leukaemias and 20 (55.5\%) out of these showed positivity favouring the diagnosis of AML, and $7(19.5 \%)$ of these showed positivity for PAS favouring a diagnosis of ALL. Cytochemistry is performed in all 36 cases, which helped in differentiating lymphoid and myeloid leukaemias. MPO and PAS stain was performed in all 36 cases, out of which 20 cases showed MPO positivity and 7 cases showed PAS positivity. Comparison of value of Immunophenotyping in diagnosis of acute leukaemia by flow cytometry, a study by Xiao et al (10) found $96.40 \%$, but in the present study $100 \%$ accuracy was resent.

Immunophenotyping was performed in 25 cases of leukaemias with ambiguous morphology. Out of 25 cases 9 were diagnosed as AML, 12 as Bcell, 3 as T-cell. One case showed both myeloid (CD13, CD33, CD117) and lymphoid differentiation (CD3, CD5) and was diagnosed as mixed lineage acute leukaemia. Comparison of role of cytogenetics in accurate sub typing of AML cases, Charrin et al [11] 14.6\% (38/260), Zheng et al (12) $27.00 \%$ (33/122), Present study $30 \%$ (6/20) was having the accurate rare for sub typing AML by cytogenetics was higher in this study as compared to other studies.

Out of 20 cases of AML, 14 cases showed normal karyotyping and 6 cases the diagnosis of AML was confirmed and further typing was possible. The specific diagnostic cytogenetic abnormalities detected include: $\mathrm{T}(8 ; 21), \mathrm{t}(15$; 17), Inv (16) (p13.1, q 22) Trisomy 8, trisomy 4, trisomy 19 were taken to be definitive evidence of AML though the abnormalities are not specific for any particular subtype. Out of 15 cases of ALL, 11 cases showed normal karyotyping and 3 cases the diagnosis of ALL was confirmed and further typing was possible. In 1 case of ALL the culture failed. In addition to the diagnosis, cytogenetic studies helped in determining hyper and hypodiploid states which paved the way for prognostication of the study population. In 30 cases, a normal modal no of chromosomes was noted. Of the 4 cases showed hyperdiplody and 1 case showed hypodiploidy 
and 1 of the cases culture failed. The variation in the accuracy of ALL diagnosed by cytogenetics in our study is probably due to slightly dilute BM samples got mostly from the paediatric age group. Some of these cases showed normal karyotype and hence accurate sub typing was not possible in these cases. In this study chromosomal abnormalities were present in 10 cases out of 36 cases (28\%) while Charrin et al [11] found chromosomal abnormalities in 378 out of 443 cases ( $85 \%)$. And in the study done by Koushal et al [7] 8 cases out of 26 cases had chromosomal abnormalities (31\%). Detection of chromosomal abnormalities depends on multiple factors like, type of leukaemia, percentage of blasts in the sample, technical experts in the culture preparation and banding.

\section{CONCLUSION}

Leukemia or leukaemia is a type of cancer of the blood or bone marrow, the incidence of various types of leukaemias varies considerably in different age groups, racial and ethnic differences too. There may be population bias, which leads to variation in the prevalence of different types of leukaemias. Out of 36 blood and bone marrow samples studied, a final diagnosis was given after correlating morphology, cytochemistry. This is helping for classification and treatment of leukaemias. Hence we conclude that in identifying the lineage specificity of various types of leukaemias and helps on arriving at a final diagnosis especially in cases with ambiguous morphology on peripheral blood smear and bone marrow examination.

\section{REFERENCES}

[1]. Lozano R, Naghavi M, Foreman K, Lim S, Shibuya K, Aboyans V, et al. (December 2012). "Global and regional mortality from 235 causes of death for 20 age groups in 1990 and 2010: a systematic analysis for the Global Burden of Disease Study 2010". Lancet. 380(9859): 2095-128.
[2]. Mathers, Colin D, Cynthia Boschi-Pinto, Alan D Lopez and Christopher JL Murray (2001). "Cancer incidence, mortality and survival by site for 14 regions of the world"(PDF). Global Programme on Evidence for Health Policy Discussion Paper No. 13. World Health Organization.

[3]. Greer John P, Baer Maria.R, Kinney Marsha.C, "Wintrobe's Clinical Hematology." 10th edition, Williams and Wilkins, volume 2, 1999, 2273.

[4]. Redaelli A, Laskin BL, Stephens JM, Botteman MF, Pashos CL. A systematic literature review of the clinical and epidemiological burden of acute lymphoblastic leukemia (ALL). Eur J Cancer Care (Engl). 2005;14(1):53-62.

[5]. Catovsky Daniel, Hoff brand Victor A, "Acute Leukemia", chapter 18 in Post graduate haematology. Hoffbrand Victor.A, Lewis Mitchell.S, Tuddenham Edward.G.D. Fourth edition, Butterworth Heinemann international editions, 1999, 337- 385.

[6]. Jean sparks, Aamir Ehsan, Shirlyn B.Mc Kenzie, "Clinical laboratory hematology."1st edition, Pearson Prentice Hall, 2004, 482-489.

[7]. Kaushal, S., Sidhu, S.S., Anand, N., Patnaik, V.V.G., Singla, Rajan K. A study of chromosomal morphology in leukaemias. J Anat. Soc. India. 2001;50(2):112-8.

[8]. Ghosh S, Shinde SC, Kumaran GS, Sapre RS, Dhond SR, Badrinath $Y$, et al. Haematologic and immunophenotypic profile of acute leukaemias: an experience at Tata Memorial Hospital Indian J Cancer. 2003;40(2):71-6.

[9]. VinSheth FJ, Sheth JJ, Patel Al, Shah AD, Verhest A., Usefulness of cytogenetics in leukaemias. Indian J Cancer. 2002;39(4):139-42.

[10]. Xiao R, Zhang R. Combined analysis of morphology, immunology, cytogenetics and Molecular biology (MICM) classification of 55 patients with Acute promyelocytic leukaemia. Zhongguo Shi Yan Xue Ye Xue Za Zhi. 2004;12(2):147-50.

[11]. Charrin C, J.P. Magaud, C. Sebban, D. Fiitre (Lyon; 72); N. Dastugue, F. Huguet-Rigal, et al. Cytogenetic abnormalities in acute lymphoblastic leukaemias. Collaborative study of the group $m$ Francais de cytogenetique, haematologique. Blood. 1996;15;87(8):3135-42.

[12]. Zheng J, Wang X, Hu Y, Yang J, Liu J, He Y, et al. A correlation study of immunophenotypic, cytogenetic and clinical features of $180 \mathrm{AML}$ patients in China. Cytometry B Clin Cytom. 2008;74(1):25-9.

How to cite this article: S. Praveena, B Indusree. A STUDY ON CLASSIFICATION OF ACUTE LEUKAEMIAS ON THE BASIS OF CHROMOSOMAL ABNORMALITIES AND MOLECULAR GENETICS. Int J Intg Med Sci 2018;5(4):613-618. DOI: 10.16965/ijims.2018.108 